\title{
Advances with Integrated Pest Management as a component of sustainable agriculture: the case of the Australian cotton industry.
}

\author{
Gary Fitt $^{1}$, Lewis Wilson ${ }^{2}$, Robert Mensah ${ }^{3}$ and Joanne Daly ${ }^{4}$ \\ ${ }^{1}$ CSIRO Entomology and Australian Cotton CRC, 120 Meiers Rd, Indooroopilly, Qld 4068. Email gary.fitt@csiro.au \\ ${ }^{2}$ CSIRO Plant Industry and Australian Cotton CRC, Australian Cotton Research Institute, Narrabri, NSW, 2390 \\ Email lewis.wilson@csiro.au \\ ${ }^{3}$ NSW Agriculture, Australian Cotton Research Institute, Narrabri, NSW, 2390. Email: Robert.Mensah@agric.nsw.gov.au \\ ${ }^{4}$ CSIRO Entomology, PO. Box 1700, Canberra ACT, 2601. Email joanne.daly@csiro.au
}

\begin{abstract}
Insect pests represent a significant limitation for production of many crops. Traditional reliance on pesticides brings significant economic costs and environmental liabilities of off-target drift, chemical residues and resistance. IPM has long been proposed as an alternative. The adoption of IPM in the Australian cotton industry provides a valuable overview of the key components of IPM and the issues around successful implementation. IPM must be founded on a thorough understanding of the ecology of pest and beneficial species and their interaction with the crop and will provide a range of tactics which must be integrated by the producer to achieve economic and environmental sustainability. The emerging era of insect-resistant transgenic cottons offers real prospects to provide a foundation for more sustainable, economically acceptable IPM with the integration of a range of non-chemical tactics and much less reliance on pesticides.
\end{abstract}

\section{Media Summary}

Integrated pest management continues to evolve some 30 years after introduction of its concepts. IPM in the Australian cotton industry now includes a year-round ecosystem approach, management of beneficial insects, more selective pesticides, transgenic varieties with two-gene insect resistance and wide use of decision support systems

\section{Key Words}

Cotton, transgenic, IPM, integrated pest management, Helicoverpa.

\section{Introduction}

Insect pests are a major constraint on production of many crops worldwide through direct yield reductions, through damage in storage and through the costs associated with attempts at control. Pest management using traditional approaches with pesticides can often be effective but imposes significant economic and environmental costs. Integrated pest management has long been proposed as a more sustainable approach for many situations, however, the adoption of a truly integrated pest management approach has been extremely patchy. More often IPM relates to integrated pesticide management.

Broadly IPM can be defined as "the careful consideration of all available pest control techniques and subsequent integration of appropriate measures that discourage the development of pest populations and keep pesticides and other interventions to levels that are economically justified and reduce or minimize risks to human health and the environment. IPM emphasizes the growth of a healthy crop with the least possible disruption to agro-ecosystems and encourages natural pest control mechanisms.” (FAO 2002).

In this paper we will illustrate the progress that has been made in implementation of IPM in field crops by reference to the Australian cotton industry where more sustainable IPM systems have been developed and where the challenges of integration and implementation are common to many other field crops. IPM in the cotton industry illustrates the key components and processes needed for successful adoption and impact.

Many aspects of IPM have been applied in the cotton industry since the late 1970s when the computer based decision support system, SIRATAC, was released to industry (Hearn and Bange 2002). The minimal IPM approach involved the simple use of sampling systems and thresholds to better time the use of pesticides. However, today IPM represents a more expansive approach which seeks to minimise pesticide use and include a broader range of tactics such as pest-resistant varieties conservation and 
augmentation of beneficial insect populations, use of selective and short residual insecticides, recognition of the compensatory capacity of the plant and various cultural control practices which have long been associated with the IPM concept.

\section{Integrated pest Management - the components and principles}

The Australian cotton industry faces a number of challenges in pest management (Fitt 1994). These include damage from key pests (the noctuid moths Helicoverpa armigera and H. punctigera, spider mites (Tetranychus urticae), aphids (Aphis gossypii) and mirids (Creontiades dilutus)); insecticide resistance in the primary pest (H. armigera) and two secondary pests (mites and aphids); escalating costs of production and environmental concerns over off-farm movement of insecticides.

To address these issues, a major research effort has focused on reducing dependence on insecticides through the development and implementation of integrated pest management (IPM) systems (Wilson et al 2004, Fitt 2002). To be valuable to the cotton industry an IPM system needed to reduce insecticide use whilst maintaining yield and early maturity and maintaining the susceptibility of pests to new selective insecticides. At the same time it needed to be practical and workable in the context of the whole farming system, and importantly be relevant to both conventional cotton and transgenic (Bt) cotton varieties which both form important components of the current industry.

Additionally growers and consultants needed to understand and accept the basic premises on which IPM is built. These were:

- the mere presence of a pest species does not justify action for control

- IPM is about containment of a pest situation, not eradication

- no single control measure can be applied to all pest complexes

- some level of damage or loss to the crop should be tolerated

- IPM utilizes a diverse array of control options to minimise pest abundance or damage, with pesticides used as the last resort.

- IPM does not seek to eliminate the use of pesticides, but aims to utilise the least disruptive options and to reduce applications overall reduce the use of pesticides for pest control to the lowest practical levels.

The Australian cotton IPM system addresses these goals through four key principles:

1. conservation and utilization of beneficial insects;

2. preferential use of selective insecticides;

3. an emphasis on both profitability and sustainability, ensuring that both input costs and yield are considered, rather than the traditional emphasis on maximizing yield; and

4. integration of all farm management activities, throughout the annual cycle of production, not just during the cotton season.

These principles were captured in the 'Guidelines for Integrated Pest Management in Australian Cotton' (Mensah and Wilson 1999 - http://www.cotton.pi.csiro.au/Assets/PDFFiles/IPMGL99/IPMGL99.pdf)).

This IPM strategy partitions the annual crop cycle into five key periods: planting to first flower; first flower to first open boll; first open boll to harvest; a post harvest period; and a pre-planting period. The three first periods deal with the growth cycle of the crop. The final two deal with the "off" season or winter period. Inclusion of the winter period was essential, since many of the actions taken through this period have important implications for the success of IPM in the following growing season. In each of these phases key non-insecticidal tools that can be used to manage pests or to enhance abundance of beneficial species were identified. These included a range of agronomic, varietal and physiological factors that are part of the farming system, but not normally thought of as pest-control tools. These include optimising fertilizer rates and irrigation strategies, the timing of the last irrigation, and the time to defoliate the crop. These factors can all be manipulated to contribute toward the goals of IPM. They also highlight that IPM requires a long-term ecosystem wide approach which must fit within a farming system context and not be perceived as an add-on. 


\section{IPM Strategies applied through the Growing Season}

Below is a list of the key IPM components utilised in Australian cotton production. Wilson et al (2004) provide more detail.

\section{Pest-tolerant varieties - the foundation}

The crop itself is the template on which a broad range of interactions between pests and their environment are formed and is thus the starting point for any IPM system. Cotton plants have a number of naturally occurring biochemical (tannins, terpenoids) and morphological (leaf shape) defences against arthropod (insects and mites) pests and a high capacity to compensate for pest damage since the plant produces many more flowerbuds than it can mature as bolls. Several conventional host-plant resistance traits have been incorporated into modern varieties. These include resistances to key diseases (bacterial blight, Verticillium) and morphological traits (okra leaf, smoothleaf) which reduce the development of pest populations. However there remains much genetic variability in insect-resistance traits and in the potential of cotton to compensate for damage (Sadras 1995, Sadras and Fitt 1997). More recently a quantum step in pest resistance has been achieved through genetically modified cottons (Ingard ${ }^{\circledR}$, Bollgard $\mathrm{II}^{\circledR}$ ) expressing the delta-endotoxin genes from Bacillus thuringiensis subsp. kurstaki (Bt). Fitt and Wilson (2000) demonstrate that insect-resistant transgenic cottons are a good platform for IPM. They reduce the need to control Helicoverpa punctigera, the primary early-season cotton pest in Australia, thereby reducing disruption to beneficial insects caused by insecticide use, and conserving and maximizing beneficial insect activity. Genetically engineered cotton is an important tool for IPM because it helps growers to realise the benefits of IPM more easily (Fitt 2003).

\section{Agronomic components}

1. Optimal planting time. Planting outside the optimal time period (early October in most established production regions) adversely affects yield potential and is counter-productive to IPM. Very early planting (mid September) in cool districts increases the risk of damage due to severe cold, slow early growth and greater susceptibility to diseases and herbicide and early pest damage, especially from thrips. Late planted cotton decreases yield potential and increases the risk of late infestations of $H$. armigera, mites and aphids that are difficult and expensive to control.

2. Optimal water management. Irrigation decisions are based on knowledge of the soil water holding capacity and objective assessment of crop need. A critical decision is the timing of the final irrigation. Unnecessary late irrigation will extend the period of attractiveness to pests but may not enhance yield potential. Optimal irrigation management can avoid this problem.

3. Strategic use of plant growth regulators. Optimal irrigation scheduling and rates of nitrogen fertilizer will generally control vegetative growth. However, excessive vegetative growth will produce crops which remain attractive to pests and mature late, thereby increasing the need to pest control. Appropriate use of growth regulators helps to reduce the severity of this problem.

\section{Use of trap-crops to concentrate pest population}

One example is the use of spring chickpea crops to capture eggs from $H$. armigera moths that emerge from over-wintering diapause (Ferguson et al. 2000). These moths are potential carriers of genes for pesticide resistance from one season to the next (Daly and Fitt 1990). Trap crops are a means to concentrate $H$. armigera populations into a limited area where they can be destroyed using biopesticides or cultivation of the trap crop thereby reducing the carry-over of resistance genes and overall population size.

A second example is the use of spring lucerne trap crops to capture adults of the green mirid, Creontiades dilutus and avoid infestation of adjoining cotton. Green mirids are important pests in cotton, often causing plants to shed squares (flower buds) or young bolls and damaging maturing bolls, causing yield loss. Green mirids prefer lucerne (new growths or shoots) to cotton. Lucerne crops adjacent to, or as strips within, cotton crops act as a sink for green mirids. By alternatively slashing half of the lucerne at four weekly intervals, new regrowth of lucerne can be maintained and the green mirids can be maintained in the lucerne without moving into the cotton (Mensah and Khan 1997). 
Conservation, enhancement and integration of predators into pest management.

Cotton fields typically harbour a rich diversity of arthropods. In Australia up to 450 different species have been recorded in unsprayed fields (L. Wilson, unpublished) and a significant proportion of these are beneficials. It is striking that the key beneficial groups in cotton are similar in many parts of the world (Hearn and Fitt 1992), but their impacts and value have often proven difficult to demonstrate.

While predators and parasites are important components of IPM systems there are often severe limitations in the capacity of beneficials to control some pests, particularly the Heliothines. These pests are highly mobile, highly fecund, well adapted to exploit diverse cropping systems (Fitt, 1989, 1994) and capable of explosive infestations of crops. Consequently an important area of research, beyond simply minimising the use of disruptive chemicals, has been to identify means to conserve, augment or manipulate beneficial populations. Conservation of natural enemies requires considerable ecological understanding of their seasonal phenology, habitat and prey requirements. Extensive research has now defined the key predators and parasitoids and their basic biology. The majority of predators are generalists, able to sustain populations on a diversity of prey types. Predator abundance can be readily monitored and estimates of abundance utilised in decision making through a predator / prey ratio which indicates when predators are sufficiently abundant to have impact (Mensah 2002a,b). Mechanisms to encourage beneficial insects include the use of nursery crops such as perennial lucerne crops which are attractive to many insects and offer a permanent habitat on-farm so providing some buffer against the unpredictability of natural populations.

\section{Rigorous and regular crop sampling.}

Regular crop sampling for pests, plant damage and beneficial insects is critical for effective IPM (Deutscher and Wilson 1999a). Regular sampling (every 3 days during crop development) means that decisions to delay control can be monitored and action taken if the situation changes while the pest population can still be effectively controlled with selective insecticides.

\section{Use of combined pest and damage thresholds.}

Thresholds are an essential tool to ensure that insecticides are only applied if economic loss is reasonably expected to occur (Deutscher and Wilson 1999b). However, thresholds based solely on pest numbers alone assume that all cotton crops respond to pest density in a similar way. Many other factors may ameliorate crop response to pests (eg vigour, disease, temperature and nutrition) such that the crop compensates for damage. Guidelines have been established for the amount of damage that plants can tolerate without loss of yield or delay (Wilson et al. 2003). By integrating compensatory responses into thresholds it is possible to identify those situations where pests may have exceeded a threshold but the crop will recover without loss, thereby avoiding use of an insecticide to prevent non-economic damage.

\section{Preferential use of selective insecticides.}

New generation insecticides are much more selective than the older suite of organophosphate, carbamate and pyrethroid pesticides which characterised Australian cotton a decade ago. A number of new compounds and chemical groups (eg. spinosad, emamectin, indoxacarb, pymetrozine, diafethiuron and methoxyfenozide) together with biologicals (NPV virus and Bt sprays) provide powerful IPM tools as they are less disruptive to beneficial populations. Independent information on the efficacy and non-target effects of all current insecticides has been obtained locally (Wilson et al. 2002). Understanding the particular characteristics of insecticides is important. For example, spinosad (Tracer ${ }^{\circledR}$ ) has a low impact on predatory Coleoptera and Hemiptera, but is very disruptive of micro-Hymenoptera (including Trichogramma), ants and thrips, which eat mite eggs (Wilson et al. 1996).

\section{'Site-specific' pest management.}

Historically cotton growers often treated the whole farm as the unit for pest management. While this practice reduced application costs and provided some streamlining of farm operations it also meant that beneficial populations could be were impacted over wide areas, leaving no refuge for beneficials to recolonise sprayed fields. By treating only fields that are over threshold with selective insecticides, this disruption can be minimised. 'Site specific management' is in a fundamental sense a type of precision agriculture. 
An effective resistance management strategy.

Australia has a long history of problems with the evolution of pesticide resistance in key pest populations, but also a world leading position in effective resistance management (Forrester et al. 1993). The IPM system needs to accommodate the need to protect new pesticide technologies. All new selective pesticides are incorporated in the Insecticide Resistance Management Strategy (IRMS) developed under the auspices of the industry based Transgenic and Insecticide Management Strategies (TIMS) committee. A rigorous and pre-emptive resistance management strategy is also in place for Bt cotton varieties (discussed later).

\section{IPM Strategies applied through the Winter}

Destruction of diapausing pupae of $\mathrm{H}$. armigera that are a potential reservoir of resistance genes (Fitt and Daly 1990). This is a core non-insecticidal component of both the IRM and IPM strategies. Growers are advised to sample cotton stubble for overwintering pupae, using published guidelines, to determine which fields require control and to prioritise those that do. Fields which have grown Bt cotton require mandatory cultivation to eliminate regrowth and destroy any potential resistant pest populations.

Selection of rotation crops to reduce pest carry-over.

Rotation crops also have implications for pest management. Some rotation crops provide an over-winter host for pests and some cotton diseases (eg. faba beans (mites, aphids), safflower (mites, mirids), chickpeas (H. armigera) or cereals (H. armigera and thrips)) At the same time winter rotations provide a seasonal refuge for beneficial insect populations. Balancing these issues needs to be taken into account in the choice of rotation crop and its management.

Management of weeds and cotton regrowth that are over-winter pest hosts.

Weeds and cotton regrowth following harvest can provide over-winter hosts for a number of pests including Helicoverpa, mites (Wilson 1994a), mirids, aphids, tipworm, cutworm, armyworm and whitefly. Poor in-field hygiene is particularly a problem with spider mites, aphids and mirids as these pests can move off the weeds and onto seedlings in the following season. Again weeds provide a refuge for beneficial species and the trade-off between pests and beneficials needs to be considered. At the scale of individual fields on farms it is likely that the safest course is for strict management of in-field weeds and regrowth.

Optimisation of fertilizer strategies to avoid excessive plant growth.

Most nitrogen fertiliser for cotton is applied prior to sowing, often several months beforehand. Nitrogen availability can directly affect pest management as well as potential yield and maturity. Too little nitrogen will decrease yield. Excessive nitrogen can create excessive end-of-season plant growth, making the crop more attractive to Helicoverpa, requiring additional inputs of expensive insecticides for control, potentially delay crop maturity by $1-2$ weeks and making crops harder to defoliate (Rochester et al. 2001). Growers are advised to manage nitrogen on a field-by-field basis based on soil tests (Constable and Rochester 1988) using DSS such as NutriLOGIC and NUTRIpak to select appropriate fertilizer rates (Deutscher and Bange 2003).

Matching of cotton variety to region and pest complex.

Australian growers have access to a wide range of varieties adapted to certain geographical regions or production situations. Selection of the most appropriate varieties for the combination of season length, yield potential, pest complex and agronomic situation is critical for IPM.

Selection of appropriate seed insecticide treatments.

By definition, the use of 'at planting' insecticides, applied in the soil (such as aldicarb or phorate) or applied directly to the seed as a seed treatment (such as imidocloprid, thiodicarb and fipronil), is 'prophylactic'. Though the main target of these insecticides is thrips, which are predators of mite eggs, they are reasonably selective against many other beneficial groups (Wilson et al. 2002). Their selectivity is based on the fact that they do not contaminate the foliage but are absorbed by the plants. Since beneficial insects do not directly feed on cotton but feed on insects on the pests, beneficial insects are unaffected by the seed insecticide treatments or in furrow application of these insecticides. Therefore in situations where there is a reasonable expectation of an economic benefit from control of thrips, the use of 
'at planting' insecticides may be a better choice than the conventional approach of treating at pest threshold.

\section{Genetically modified cottons in IPM}

Genetically engineered cottons expressing the delta-endotoxin genes from Bacillus thuringiensis subsp. kurstaki (Bt) offer great potential to dramatically reduce pesticide dependence for control of the major lepidopteran pests and consequently offer real opportunities as a component of sustainable and environmentally acceptable IPM systems.

Bt cotton varieties expressing the Cry 1Ac protein were first registered in Australia in 1996 (INGARD ${ }^{\circledR}$ ). Fitt (2003; 2004) provide a comprehensive assessment of the impact of Bt cotton in Australia over the first six years of commercial use. While efficacy of INGARD cottons is not consistent through the growing season and can be highly variable (Fitt et al, 1994; Fitt et al., 1998), growers have learned to manage INGARD varieties and substantial reductions in pesticide use on Bt cotton have occurred. Reductions in the number of sprays applied for Helicoverpa have averaged 56\% with no significant change in pesticide applications for minor pests (Fitt 2004). As discussed later there have been simultaneous reductions in pesticide use on conventional cotton.

The most consistent “winner” from INGARD ${ }^{\circledR}$ technology has been the environment, with reduced pesticide loads, while the cotton industry has gained long term sustainability through the progressive adoption of more integrated pest management approaches using INGARD ${ }^{\circledR}$ cotton as a foundation. With progressive improvement in varietal performance and experience of growers and consultants in managing the technology economic returns have also been substantial.

The major challenge to sustainable use of transgenic Bt cottons is the risk that target pests, particularly $H$. armigera, may evolve resistance to the CryIAc protein. For this reason a pre-emptive resistance management strategy was implemented to accompany the commercial release of transgenic varieties (Roush et al., 1998). The strategy, based on the use of structured refuges to maintain susceptible individuals in the population (Roush et al., 1998), seeks to take advantage of the polyphagy and local mobility of $H$. armigera to achieve resistance management by utilising gene flow to counter selection in transgenic crops. By contrast, extensive natural refuges effectively nullify the resistance risk in $H$. punctigera. Indeed $H$. punctigera provides an excellent natural example of the capacity of the refuge strategy to reduce resistance risk

Key elements of the INGARD ${ }^{\circledR}$ cotton resistance management strategy are:

1. effective refuges on each farm growing INGARD ${ }^{\circledR}$ cotton

2. defined planting window for INGARD ${ }^{\circledR}$ cotton to avoid late-planted crops that may be exposed to abundant $H$. armigera late in the growing season

3. mandatory cultivation of INGARD ${ }^{\circledR}$ crops and crop residues after harvest to destroy most overwintering pupae of $H$. armigera

4. removal of volunteer INGARD ${ }^{\circledR}$ plants

5. defined spray thresholds for Helicoverpa to ensure any survivors in the crops are controlled

6. monitoring of Bt resistance levels in field populations

Australian growers can currently choose from 5 different refuge options (sprayed conventional cotton, unsprayed cotton, sorghum, maize or pigeon pea) each with a different area determined by the relative productivity of the refuge (Fitt and Tann 1996). Refuge crops cannot be treated with Bt sprays, and must be in close proximity to the transgenic crops (within $2 \mathrm{~km}$ ) to maximise the chances of random mating among sub-populations (Dillon et al., 1998).

An additional element of the strategy was a phased introduction of INGARD ${ }^{\circledR}$ varieties and a cap on the area at $30 \%$ of the total cotton area. In their first year INGARD ${ }^{\circledR}$ varieties were grown on 30,000 ha representing about $8 \%$ of the total cotton area in that year. After that the area increased in $5 \%$ increments each year up to the $30 \%$ cap. BOLLGARD II $^{\mathrm{TM}}$ varieties with two Bt genes (Cry IAc, Cry 2Ab) have now been approved for commercial use and occupy about 5,000 ha in 2002/03. The two gene varieties provide much better efficacy and hence even greater reduction in pesticide requirement, but their main purpose is to provide much greater resilience against the risk of resistance (Roush, 1998). A rapid transition to BOLLGARD II $^{\mathrm{TM}}$ is planned, with INGARD ${ }^{\circledR}$ varieties withdrawn after the 2003/04 season. From 
2004/05 onwards only BOLLGARD II ${ }^{\mathrm{TM}}$ varieties are available, so removing the risk of mixed deployment of single gene and two gene varieties. This strategy is significantly different to the likely course in the US cotton industry where no mandated change to two gene varieties is in place. From 2004/05 onwards the cap of Bt cotton will also be lifted although all other components of the resistance management strategy remain unchanged.

INGARD $^{\circledR}$ and BOLLGARD II $^{\mathrm{TM}}$ cotton varieties are not perceived as "magic bullets” for pest control in Australia. Instead they are viewed broadly as an opportunity to address environmental concerns about cotton production and more specifically as a foundation to build IPM systems which incorporate a broad range of biological and cultural tactics (Fitt, 2000; Wilson et al., 2004). Research has shown little effect of Bt cottons on non-target species, including non-lepidopterous pests, beneficial insects, and other canopy-dwelling and soil-dwelling species (Fitt, 2000; Fitt and Wilson, 2002). Survival of beneficials is markedly higher than in conventional sprayed cotton, and they provide control for some secondary pests, particularly those that are induced pests in sprayed cotton (eg. mites and aphids).

\section{Extension and implementation of IPM}

Defining and formalising an IPM system is just the first step. Achieving effective implementation requires a consistent and coherent communication and extension effort. The cotton industry has been well served by a National Cotton Extension Team resourced largely by the Cotton R\&D Corporation and the Australian Cotton CRC and by a highly professional core of professional consultants. The extension team has representatives in all the main cotton regions, and provides a highly coordinated vehicle for consistency and co-operation in providing information.

The extension team used a range of strategies to deliver the IPM system (Christiansen 2002). These included field days to discuss IPM issues, co-ordinated experiments and demonstrations across several regions, production of regular newsletters, the published IPM Guidelines themselves, together with other technical information which forms ENTOpak. This compendium of pest management information includes the IPM guidelines, a pest and beneficial identification guide, and supporting documents providing detailed information on pest thresholds, sampling, pupae control, selectivity of insecticides, crop damage monitoring and planning of last irrigation. Importantly these documents are cross-referenced to other 'Paks' which provide support in implementing IPM, for instance MACHINEpak, NUTRIpak, WEEDpak and DISEASEpak, all of which include issues or approaches relevant to IPM.

As part of a drive to enhance environmental management of cotton farms, the industry has implemented a Best Management Practice (BMP) approach (Williams and Williams 2000). This provides a framework for growers to evaluate their management performance against the best standards in the industry, for identifying areas of improvement, and documenting this in an auditable fashion. The core principles of the IPM guidelines form one module in the 'Best Management Practice' Manual. This provides growers with a means to assess how they are progressing in adopting IPM principles on their farm.

Effective extension has also fostered the development of regional IPM groups, where groups of growers agree on core goals and communicate throughout the season to achieve a local regional approach to pest management. In some instances this participatory research approach (Dent 1995) has grown to a truly area-wide management system where pest management efforts are co-ordinated across a region by using understanding of the pests' ecology and interactions with the farming system to reduce abundance (Ferguson et al. 2002).

Since the inception of the SIRATAC system, computer based decision support systems (DSS) have been a feature of the Australian cotton industry. The CottonLOGIC suite of DSS provides support for the key elements of IPM and provides a benchmark against which decisions can be compared (Deutscher and Bange 2003). CottonLOGIC on the Palm ${ }^{\circledR}$ OS has provided further flexibility with a portable system to support objective sampling for pests and beneficials, access to pest development models and yield loss predictions (Hearn and Bange 2002) and previous crop history all in the field. Data can later be downloaded for more thorough analysis of pest and crop performance.

The final critical factor in gaining support for IPM systems has come from favourable economic analyses of IPM. Hoque et al. (2000) analysed grower information and showed that the "soft", IPM approach 
generally had gross margins equal to or higher than a more traditional approach using "hard", more disruptive chemicals. The difference was attributed to higher beneficial insect populations in the fields managed with more selective insecticides. This analysis was critical in providing 'economic' credibility for the IPM approach. Such studies have now been extended to other regions with similar findings.

\section{Impacts of IPM}

Adoption of an IPM approach, incorporating many of the elements above, has had a dramatic uptake over the past 4 years (Christiansen and Dalton 2002). There has been significant change in grower attitudes over the past 5 years, increased uptake and use of the CottonLOGIC DSS for its scientific values in IPM decision support as well as for accurate record keeping (Deutscher and Bange 2003). More importantly there have been significant reductions in pesticide use (expressed as active ingredient) on both conventional and transgenic crops (Figure 1), achieving environmental gains and enhancing future sustainability of the industry.

Care must be taken in interpretation of Figure 1 since insecticide use is linked to pest abundance and Helicoverpa has been at relatively low densities during the prolonged drought in many cotton areas. Likewise several newer pesticides are active at much lower concentrations than the pesticides they replaced. It also seems unlikely that the reduction in pesticide use on conventional cotton results from the regional impact of Bt cotton on Helicoverpa abundance since over the period shown the area of Bt cotton was limited to a maximum of $30 \%$ of the cotton in a region. A number of factors are likely involved here, but one important possibility is that the coincident release of Bt cotton and the industry wide extension effort on IPM, allowed many growers to build confidence in the potential for IPM by managing their Bt cotton crops. They were able to become more comfortable with seeing a "living" crop, filled with numerous and mostly innocuous or beneficial insects, more attuned to the critical importance of managing agronomic inputs, and more willing to work cooperatively with neighbours through the IPM and areawide groups. It will be instructive to view the ongoing management of conventional cotton and the performance and adoption of BOLLGARD II $^{\mathrm{TM}}$ cotton varieties now that the $30 \%$ cap on Bt varieties is lifted.

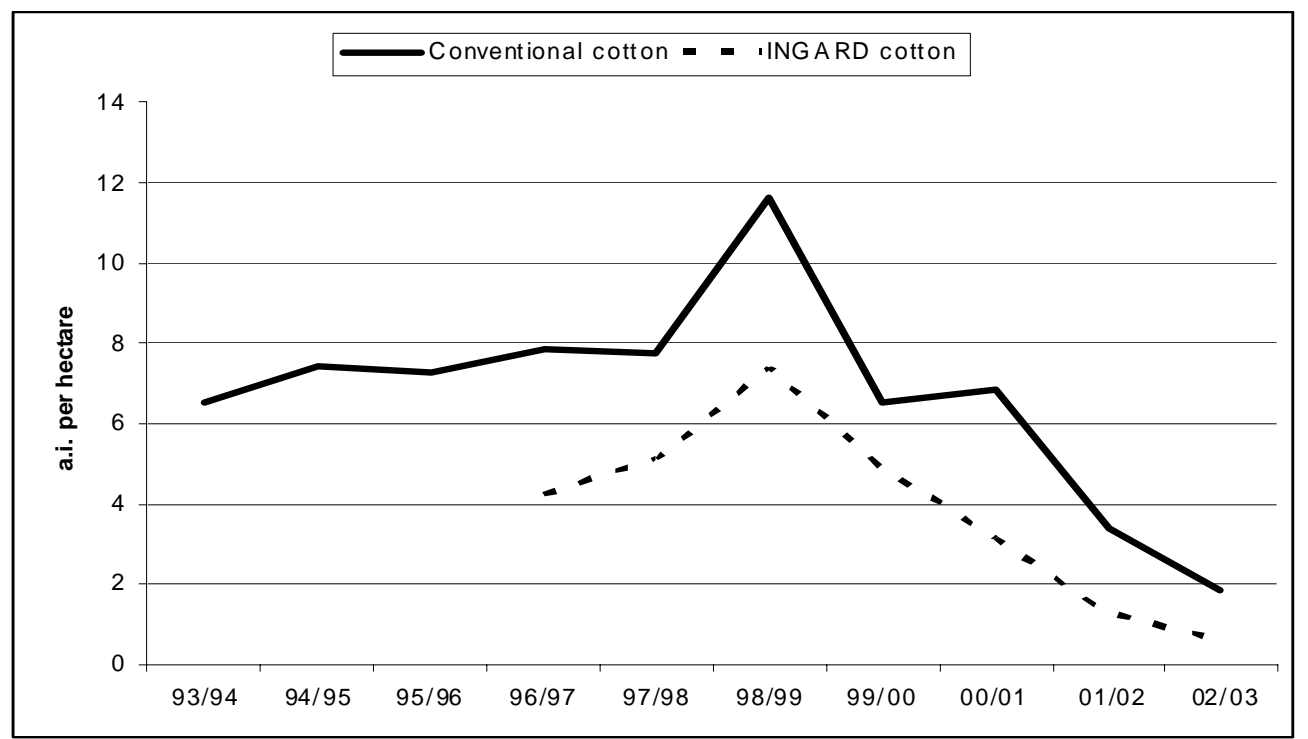

Figure 1. Change in Pesticide Use (kilograms of Active Ingredient per Hectare) on Australia cotton crops. Significant reductions have been achieved on both conventional and INGARD ${ }^{\circledR}$ cottons over the last 5 years. Source: Cotton Consultants Association Market Audit Survey 2003. 


\section{Conclusions}

IPM systems for future production of many broadacre and horticultural crops will, of necessity, be more complex than the pesticide-based systems currently in place, and will require greater effort on the part of crop managers whether they be professional consultants or farmers themselves. In essence IPM reflects a sound interaction of science and pragmatism to achieve productive, viable and sustainable production systems. A key ingredient will always be investment in education and extension to build on the values of sound science.

As farming systems change the pest complex will also change. The fundamental role of IPM in reducing pest pressure and insecticide use means that it must continue to evolve. This is particularly so in highvalue, high-input production systems such as cotton. For Australian cotton ongoing improvements in IPM adoption are likely to flow from the introduction of Bollgard II varieties with two Bt genes. In taking a farming systems and participatory approach our IPM framework will maintain effective engagement between research, extension services and industry to ensure the continued evolution and implementation of our IPM.

\section{References}

Christiansen I (2002) Extension and Profitability - Implementation of Profitable and Sustainable Approaches. Proceedings $11^{\text {th }}$ Australian Cotton Conference, ed D. Swallow, pp. 65-74

Christiansen I, Dalton B (2002) Understanding IPM - Industry attitudes, practices and education. Proceedings $11^{\text {th }}$ Australian Cotton Conference, ed D. Swallow, pp. 189-196

Constable G, Rochester I (1988). Nitrogen application to cotton on clay soil: Timing and soil testing. Agronomy Journal 80:498-502

Daly, J.C. and G.P. Fitt (1990). Resistance frequencies in overwintering pupae and the spring generation of Helicoverpa armigera (Lepidoptera: Noctuidae): selective mortality and gene flow. Journal of Economic Entomology 83(5): 1682-1688

Dent DA (1995) Integrated Pest Management. Chapman and Hall, London

Deutscher S, Bange M (2004). Advancement in computerised decision support systems for Australian cotton systems. Proceedings of the World Cotton Research Conference 3, Cape Town, South Africa.(in press)

Deutscher S, Wilson L (1999a). Insect and damage sampling for cotton. IPM Guidelines Supporting Document 1, Australian Cotton Cooperative Research Centre, Narrabri, NSW, Australia. pp 4.

Deutscher S, Wilson LJ (1999b). Insect thresholds. In: ENTOpak - IPM Guidelines Supporting Document 8., Australian Cotton Cooperative Research Centre, Narrabri, NSW, Australia

Dillon, M.L., Fitt, G.P. and Zalucki, M.P., (1998). How should refugia be placed upon the landscape? A modelling study considering pest movement and behaviour. In: M.P. Zalucki, R.A.I Drew and G.G. White (Editors), Pest Management - Future Challenges. University of Qld Press, Brisbane. pp.179189.

FAO Code of Conduct on Pesticides’ definition (2002): Integrated Pest Management (IPM)

Ferguson J, Miles M, Murray D, Dillon M, Kauter G, Lloyd R, Sequeira R (2000). Spring trap crop management guidelines. Australian Cotton Cooperative Research Centre, Narrabri, NSW, Australia, $12 \mathrm{pp}$

Ferguson J, Miles M (2002). Area wide management on the Darling Downs - has it worked? Proceedings of the Australian Cotton Growers Research Conference, Brisbane, August, 2002

Fitt, G.P., (1989). The ecology of Heliothis species in relation to agroecosystems. Annual Review of Entomology, 34: 17-52.

Fitt, G.P., (1994). Cotton pest management: Part 3. An Australian perspective. Annual Review of Entomology 39: 543-562.

Fitt, G.P. (2000). An Australian approach to IPM in cotton: integrating new technologies to minimise insecticide dependence. Crop Protection 19: 793-800 Fitt, G.P. (2003). Deployment and impact of transgenic Bt cottons in Australia. PP. 141 - 164 In "The Economic and Environmental Impacts of Agbiotech: A Global Perspective”, Kalaitzandonakes, N.G. (Editor), Kluwer, New York. 
Fitt, G.P. (2004). Implementation and impact of transgenic Bt cottons in Australia. Pp. 371-381 in Cotton Production for the New Millennium. Proceedings of the third World Cotton Research Conference, 913 March, 2003, Cape Town, South Africa, 1778 pages. Agricultural Research Council - Institute for Industrial Crops, Pretoria, South Africa.

Fitt, G.P. and Daly J.C. (1990). Abundance of overwintering pupae and the spring generation of Helicoverpa spp. (Lepidoptera: Noctuidae) in northern New South Wales, Australia: Implications for pest management. Journal of Economic Entomology 83: 1827-1836

Fitt, G.P. and Tann, C (1996). Quantifying the value of refuges for resistance management of transgenic Bt cotton. Proceedings Australian Cotton Conference, ed D. Swallow, pp. 77-83.

Fitt, G.P. and Wilson, L.J. (2000). Genetic Engineering in IPM: Bt cotton. pp. 108-125 In: Kennedy, G.G. and Sutton, T.B. (eds). Emerging Technologies in Integrated Pest Management: Concepts, Research and Implementation. APS Press, St. Paul.

Fitt, G.P., Daly, J.C., Mares, C.L. and Olsen. K., (1998). Changing Efficacy of Transgenic Bt Cotton Patterns and Consequences. In: M.P. Zalucki, R.A.I Drew and G.G. White (Editors), Pest Management - Future Challenges. University of Qld Press, Brisbane., pp.189-196.

Fitt, G.P., Mares, C.L. and Llewellyn, D.J., (1994). Field evaluation and potential impact of transgenic cottons (Gossypium hirsutum) in Australia. Biocontrol Science and Technology, 4: 535-548.

Forrester, N.W., Cahill, M., Bird, L.J. and Layland, J.K., (1993). Management of pyrethroid and endosulfan resistance in Helicoverpa armigera (Lepidoptera: Noctuidae) in Australia. Bulletin of Entomological Research Supplement No.1., 132pp.

Hearn A, Bange M (2002). SIRATAC and CottonLOGIC: persevering with DSSs in the Australian cotton industry. Agricultural Systems 74:27-56

Hearn, A.B. and Fitt, G.P., (1992). Cotton cropping systems. In: Pearson C. (Editor), Field Crop Ecosystems of the World. Elsevier Press, Amsterdam, pp. 85-142.

Hoque Z, Farquharson B, Dillon M, Kauter G (2000). Soft options can reduce costs and increase cotton profits. Australian Cottongrower 21:33 - 37

Mensah R (2002a) Development of an integrated pest management programme for cotton. Part 1: Establishing and utilising natural enemies. International Journal of Pest Management 48:87-94

Mensah R (2002b) Development of an integrated pest management programme for cotton. Part 2: Integration of a lucerne/cotton interplant system, food supplement sprays with biological and synthetic insecticides. International Journal of Pest Management 48:95-105

Mensah RK, Khan M (1997) Use of Medicago sativa interplantings/trap crops in the management of the green mirid, Creontiades dilutus in commercial Australia. International Journal of Pest Management 43:197-202

Rochester I, Peoples M, Constable G (2001) Estimation of the N fertiliser requirements of cotton grown after legume crops. Field Crops Research 70:43-53

Roush, R.T., (1998). Two toxin strategies for management of insecticidal transgenic crops: Can pyramiding succeed where pesticide mixtures have not? Phil. Trans. Royal Soc. London, Series B, Biological Sciences, 353: 1777-1786.

Roush, R.T., Fitt, G.P., Forrester, N.W, Daly, J.C. (1998) Resistance Management for Insecticidal Transgenic Crops: Theory and Practice. pp.247- 257 In: M.P. Zalucki, RAI Drew, GG White eds. Pest Management - Future Challenges. Proceedings of the 6th Australasian Applied Entomology Conference, Brisbane. University of Qld Press, Brisbane

Sadras, V.O. and Fitt, G.P., (1997). Resistance to insect herbivory of cotton lines: quantification of recovery capacity after damage. Field Crops Research, 52: 129-136.

Sadras, V.O., (1995). Compensatory growth in cotton after loss of reproductive organs. Field Crops Research, 40: 1-18.

Williams A, Williams J (2000) Australian Cotton Industry Best Management Practices Manual. Cotton Research and Development Corporation, Narrabri, NSW, Australia.

Wilson LJ (1994) Habitats of two-spotted spider mites (Acari:Tetranychidae) during winter and spring in a cotton-producing region of Australia. Environmental Entomology 24:332-340 
Wilson LJ, Bauer LR, Walter GH (1996) 'Phytophagous' thrips are facultative predators of two-spotted spider mites (Acari:Tetranychidae) on cotton in Australia. Bulletin of Entomological Research 86:297-305

Wilson L, Mensah R, Dillon M, Wade M, Scholz B, Murray D, Heimoana V, Lloyd R. (2002) Impact of insecticides and miticides on predators in cotton, December 2002 update. IPM Guidelines Supporting Document 1, Australian Cotton Cooperative Research Centre, Narrabri, NSW, Australia. pp 2.

Wilson LJ, Sadras VO, Heimoana SC, Gibb D (2003) How to succeed by doing nothing: cotton compensation after simulated early season pest damage. Crop Science 43: 2125-2134.

Wilson L.J.,Mensah R.K., Fitt G.P. (2004). Implementing Integrated Pest Management in Australian Cotton, pp. 97-118. In: A.R. Horowitz, I. Ishaaya (Eds.), Insect Pest Management: Field and Protected Crops, Springer, Berlin, Heidelberg, New York. 